\title{
The correlation between increased reactivity of the bronchi and of mediator releasing cells in asthma
}

\author{
H. J. NEIJENS, H. J. DEGENHART, R. RAATGEEP and \\ K. F. KERREBIJN
}

Department of Paediatrics, Subdepartment of Respiratory Diseases, Erasmus
University Medical School, Sophia Children's Hospital, Rotterdam, The Netherlands

(Received 4 February 1980; accepted for pablication 24 March 1980)

\section{Summary}

The hypothesis that increased reactivity in asthma is not always limited to the bronchi but also exists in the mediator releasing system was investigated in forty-five asthmatic children, approximately half of whom had exercise-induced bronchoconstriction (EIB). The bronchial threshold to histamine was measured as an indicator of the reactivity of the bronchi and the histamine release from leucocytes without adding allergen (spontaneous histamine release) was considered as an indicator of the reactivity of the basophil leucocytes. There was a significant correlation between the histamine threshold and spontaneous histamine release and between these and EIB. These findings support the hypothesis.

\section{Introduction}

Many asthmatic patients show exercise-induced bronchoconstriction (EIB) (Bierman, Kawabori \& Pierson, 1975). These patients often have bronchial hyperreactivity to histamine and acetylcholine (Kiviloog, 1973). Because of the protective action of sympathomimetics, parasympatholytics (Godfrey \& König, 1976) and disodium cromoglycate (Davies, 1968), it can be assumed that both the autonomic nervous system and mediator release play a role in the mechanism of ElB.

When measuring histamine release from leucocytes in asthmatic patients sensitive to cat dander allergen, we noticed that histamine was sometimes released in incubations without allergen (Neijens et al., 1979).

We called this phenomenon 'spontaneous histamine release'. Spontaneous histamine release is considered as a measure of the reactivity of leucocytes. In this study we have investigated the hypothesis that in asthma increased reactivity is not limited to the airways but also exists in other systems such as mediator-releasing cells. We have investigated this in patients with EIB. Because it is difficult to obtain live human pulmonary mast cells, leucocytes have been studied.

Correspondence: Drs H. J. Neijens and K. F. Kerrebijn, Sophia Children's Hospital, Gordelweg 160, 3038 GE Rotterdam, The Netherlands. 


\section{Materials and methods}

Forty-four asthmatic children (thirty-one boys, fourteen girls), who were under treatment in the outpatient department for respiratory diseases of the Sophia Children's Hospital in Rotterdam were investigated. Their mean age was 10.7 years with a range of 6.2-14.2 years. They had been in a symptom-free period for at least 4 weeks. Treatment was stopped $48 \mathrm{hr}$ before the investigations, which were carried out between $09 \mathrm{~h} 00 \mathrm{~min}$ and $11 \mathrm{~h} 00 \mathrm{~min}$. Histamine threshold was measured in the asthmatic children by means of inhalation at a flow of $6 \mathrm{1} / \mathrm{min}$ of histamine diphosphate in increasing dose concentrations of $1,2,4,8,16,32$ and $64 \mathrm{mg} / \mathrm{ml}$ (de Vries et al., 1964). At the beginning of the inhalation each patients performed a submaximal vital capacity manoeuvre after which they inhaled the aerosol at tidal volume for $30 \mathrm{sec}$. With this technique the bronchial threshold to histamine in healthy children is $\geqslant 32 \mathrm{mg} / \mathrm{ml}$.

On the morning before the histamine threshold measurement, venous blood was withdrawn, with the patient at rest, some minutes after venapuncture to minimize variations caused by the procedure (Simon et al., 1977). Spontaneous histamine release was determined by measuring the amount of histamine released from $1 \mathrm{ml}$ of leucocyte suspension incubated without allergen using the method of May et al. (1970). Histamine release was also measured after adding $20 \mu \mathrm{l}$ anti-IgE (Behring Werke 400000 i.u. $/ \mathrm{ml}$ ) in order to estimate allergen-induced histamine release. The leucocyte suspension was in contact with open air. The histamine release measurements were done in all asthmatic and in thirteen healthy persons comparable in age and sex but without a history of asthma or eczema. All measurements were done in triplicate and the values given are the average of these. The standard deviation of triplicate measurements was $0.5 \mu \mathrm{g} / \mathrm{l}$. The number of basophils was counted in duplicate by the method of Moofe $\&$ James (19.53). The bronchial reaction to exercise was measured in the asthmatic children by running up and down stairs for at least $5 \mathrm{~min}$ and was performed on the day after the histamine threshold. Exercise was considered satisfactory if the pulse rose above 175 beats a minute. Lung function was assessed by spirometry before, immediately after and at 5, 10, 15, 20 and $30 \mathrm{~min}$ after exercise. A decrease in the forced expiratory volume in $1 \mathrm{sec}\left(\mathrm{FEV}_{1}\right)$ below $85 \%$ of the initial value within $15 \mathrm{~min}$ of the run was considered as bronchoconstriction. Most of the paramaters were found to be distributed abnormally as appeared from tests for skewness and kurtosis, therefore the statistical treatment of the data was done with non-parametrical tests.

\section{Results}

Figure 1 shows that the spontaneous histamine release is higher in patients with EIB than in either those without EIB (Fisher exact test, $P<0.02$ ) or than in healthy children $(P<0.05)$. The medians of the three groups were respectively $2 \cdot 4,1$ and $1 \mu \mathrm{g} / \mathrm{l}$. No relationship between other parameters and spontaneous histamine release could be detected. The basophil counts in the respective groups were $31 \pm 25,37 \pm 16$ and $20 \pm 16 / \mathrm{ml}$ (mean \pm s.d.). Anti-IgE induced histamine release in these groups was, respectively, $9 \cdot 0 \pm 7 \cdot 2,7 \cdot 5 \pm 5 \cdot 4$ and $4 \cdot 6 \pm 3 \cdot 0 \mu \mathrm{g} / \mathrm{l}$ (mean \pm s.d.). Initial $F E V_{1}$ and spontaneous histamine release were also not related (Spearman $\rho=0.03$, not significant).

It can be seen in Fig. 2 that the relationship between the histamine threshold and the decrease after exercise is very significant (Spearman $\rho=0.69, P<0.001$ ). In patients with EIB the histamine threshold is significantly lower than in patients without EIB ( $\chi^{2}$ test, $P<0 \cdot 005$ ). The medians were 4 and $16 \mathrm{mg} / \mathrm{ml}$ respectively. 


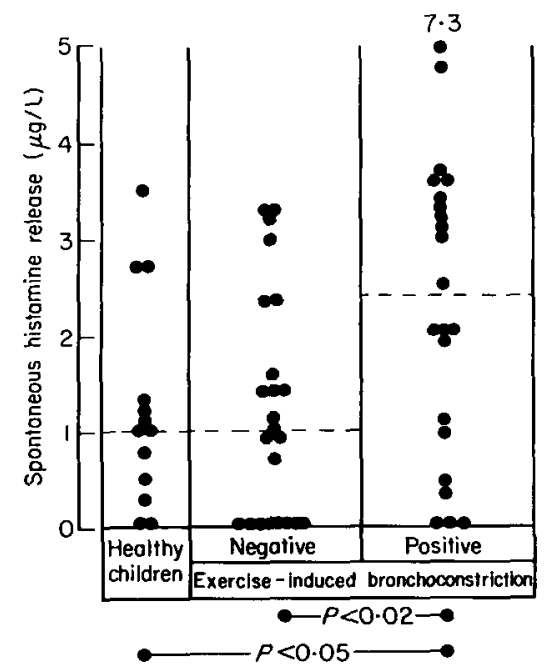

Fig. 1. Spontaneous histamine release in asthmatic children, divided according to their sensitivity to exercise, and in healthy children. Fisher exact test. Separation of the groups at $1.5 \mu \mathrm{g} / \mathrm{l}$ level, but this was not critical. --- , Median.

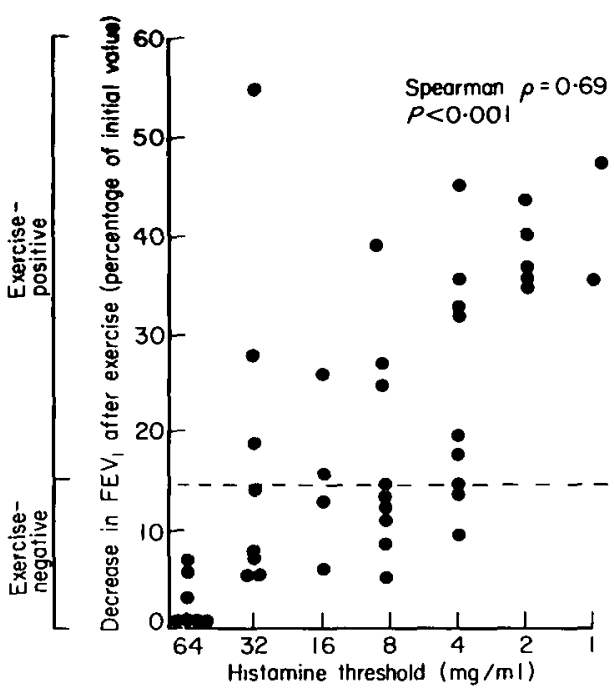

Fig. 2. Relationship between histamine threshold and exercise-induced decrease in $F E V_{1}$ in asthmatic children. Spearman $\rho=0.69 ; P<0.001$.

Figure 3 shows that fourteen out of the seventeen patients with a histamine threshold of $\leqslant 4 \mathrm{mg} / \mathrm{ml}$ also have a spontaneous histamine release of $\geqslant 1.5 \mu \mathrm{g} / \mathrm{l} ; 13$ of these have EIB. Eight of the twenty-eight patients with a histamine threshold of $\geqslant 8$ $\mathrm{mg} / \mathrm{ml}$ have a spontaneous histamine release of $\geqslant 1.5 \mu \mathrm{g} / \mathrm{l} ; \mathrm{t}$ wo of these have EIB. Six of the twenty patients in whom the histamine threshold is $\geqslant 8 \mathrm{mg} / \mathrm{ml}$ and the spontaneous histamine release $\leqslant 1.5 \mu \mathrm{g} / \mathrm{l}$ have EIB. 


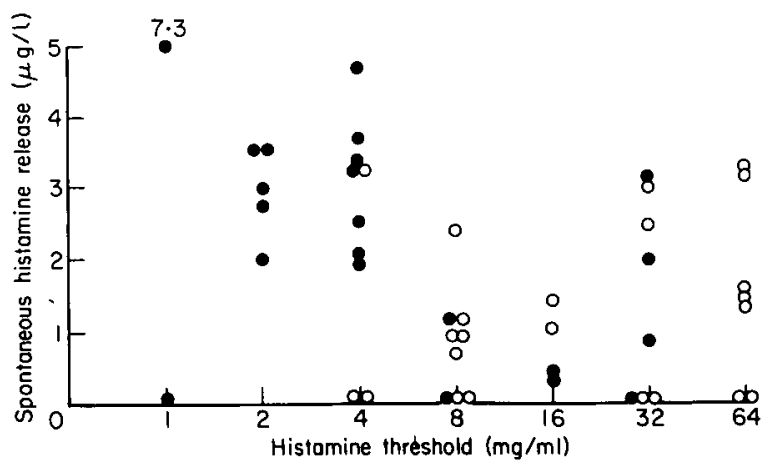

Fig. 3. Relationship between the histamine threshold and spontaneous histamine release in relation to bronchoconstriction. Spearman $\rho$ between spontaneous histamine release and histamine threshold $=0 \cdot 30$; $P<0.025$. Exercise, positive; o, exercise, negative.

From Fig. 3 it also appears that a correlation exists between the degree of spontaneous histamine release and the histamine threshold (Spearman $\rho=0.30$, $P<0.025)$, whereby the reaction to exercise was not taken into account.

\section{Discussion}

The results of this study indicate that leucocytes from asthmatic patients with EIB often have a greater spontaneous histamine release than leucocytes of both asthmatic patients without EIB and healthy children. This indicates that the leucocytes of a number of patients with EIB in the absence of a known trigger but under carefully standardized conditions, have a greater releasing capacity per unit time. This could not be explained by a difference in the number of basophils; nor by a difference in allergen-induced histamine release as judged by anti-IgE induced release in patients with and without EIB.

Further the state of the asthmatic disease was not relevant because all patients had been in a symptom-free period for at least 4 weeks and no relationship existed with the initial lung function values.

Findlay \& Lichtenstein (1978) showed that leucocytes of patients with intrinsic asthma released a greater amount of histamine after adding deuterium oxide compared to those of healthy subjects. This may indicate a difference in releasability. May (1976) found that leucocytes of patients with food allergy often had high spontaneous histamine release. Podleski and Grimes (1978) demonstrated hyperreactivity in lymphocytes of patients with obstructive airways disease.

Like others (Mellis et al., 1978; Eggleston, 1979) we found that the decrease in FEV , after exercise is strongly correlated with the histamine threshold. The histamine threshold reflects the degree of bronchial hyperreactivity of non-allergic stimuli (de Vries et al., 1964). The degree of spontaneous histamine release correlates well with the degree of bronchial hyperreactivity as is shown in Fig. 3. This supports our hypothesis that in asthmatic patients hyperreactivity may not only be present in the bronchi but also in the mediator releasing system.

\section{Acknowledgments}

This work was supported by a grant from the Dutch Asthma Foundation (project 
number 238). The authors thank Miss I. Dekker for performing the basophil counts and Dr R. G. Pearse for help in correcting our English.

\section{References}

Bierman, C.W., Kawabori, J. \& Pierson, W.C. (1975) Incidence of exercise-induced asthma in children. Pediatrics, 56, 847.

DAVIES, S.E. (1968) Effect of disodium cromoglycate on exercise-induced asthma. British Medical Journal, 3, 593.

EGGLESTON, P.A. (1979) The role of bronchial hyperreactivity in exercise-induced asthma. Journal of Allergy and Clinical Immunology, 63, 104.

FindLAY, S.R. \& LiCHTENSTEIN, L.M. (1978) Basophil releasability in patients with intrinsic asthma. Journal of Allergy and Clinical Immunology, 61, 157.

GODFREY, S. \& KÖNIG, P. (1976) Inhibition of exercise-induced asthma by different pharmacological pathways. Thorax, 31, 137.

KiviLOoG, J. (1973) Variability of bronchial reactivity to exercise and methacholine in bronchial asthma. Scandinavian Journal of Respiratory Diseases, 54, 359.

May, C.D., Lyman, M., Alberto, R. \& Cheng, J. (1970) Procedures for immunochemical study of histamine release from leucocytes with small volume of blood. Journal of Allergy and Clinical Imununology, 46, 12.

MAY, C.D. (1976) High spontaneous release of histamine in vitro from leucocytes of persons hypersensitive to food. Journal of Allergy and Clinical Inmunology, 58, 432.

Mellis, C.M., Kattan, M., Keens, T.G. \& Levison, H. (1978) Comparative study of histamine and exercise challenges in asthmatic children. American Review of Respiratory Disease, 117, 911.

MOORE, J.E. \& JAMES, G.W. (1953) Proceedings of the Society for Experimental Biology, New York, 82, 601.

Neijens, H.J., Degenhart, H.J., Raatgeep, H.C. \& Kerrebijn K.F. (1979) Study of the significance of bronchial hyperreactivity in the bronchus obstruction after inhalation of cat dander allergen. Journal of Allergy and Clinical Immunology, 67, 507.

PODLESKI, W.K. \& Frimes J.R. (1978) Circulating hyperreactive lymphocytes in bronchial asthma. Clinical Immunology and Immunopathology, 9, 236.

Simon, R., Stevenson, D.D., Arroya ve, C.M. \& Tan E.M. (1977) The relationship of plasma histamine to the activity of bronchial asthma. Journal of Allergy and Clinical Immunology, 60, 312.

de Vries, K., Booy-Noord, H., Goei, H., Grobler, N.J., Sluiter, H.J., Tammeling, G.J. \& Orie, N.G.M. (1964) Hyperreactivity of the bronchial tree to drugs, chemical and physical agents. In: Bronchitis. II (eds N.G.M. Orie and H. J. Sluiter), p. 167. Royal van Gorcum, Assen. 
This document is a scanned copy of a printed document. No warranty is given about the accuracy of the copy. Users should refer to the original published version of the material. 